\title{
The energy and nutrient intakes of different types of vegetarian: a case for supplements?
}

\author{
BY ALIZON DRAPER ${ }^{1 *}$, JANET LEWIS ${ }^{2}$, NINA MALHOTRA ${ }^{1}$ \\ AND THE LATE ERICA WHEELER ${ }^{1}$ \\ ${ }^{1}$ Centre for Human Nutrition, Department of Public Health and Policy, London School of Hygiene \\ and Tropical Medicine, 2 Taviton Street, London WC1H OBT \\ ${ }^{2}$ Ministry of Agriculture, Fisheries and Food, Nobel House, 17 Smith Square, London SWI
}

(Received 26 March 1991 - Accepted 7 January 1992)

\begin{abstract}
Vegetarians of three types were studied in Greater London: thirty-four meat-avoiders, fifty-two lactoovo-vegetarians, and thirty-eight vegans. Weighed dietary intake measures were made over $3 \mathrm{~d}$. Cereals were the mainstay of the diet, supplemented by dairy products (demi-vegetarians and lacto-ovovegetarians), vegetables and fruit, and soya-bean products (vegans). Many vegans progressed by stages to complete avoidance of animal foods; some had retreated, but most were highly committed. Demivegetarians were the least involved in a 'vegetarian lifestyle'. All groups had mean energy intakes close to the current dietary reference values (DRV), with adequate protein intakes. Only vegans had fat intakes close to current recommendations; all groups had high dietary polyunsaturated:saturated fatty acid ratios. Mean intakes of all micronutrients studied for demi- and lacto-ovo-vegetarians met the UK DRV. Intakes of iodine, riboflavin, and vitamin $B_{12}$ for vegans were below DRV; more than half considered their diets supplied all necessary vitamins. About $25 \%$ took some type of dietary supplement during the survey. The impact of low I intakes should be further studied, and it is recommended that 'new' vegetarians and vegans should use appropriate dietary supplements.
\end{abstract}

Vegetarian: Vegan: Macronutrients: Micronutrients: Dietary supplements

During the past 20 years there has been an increase in the numbers of people who reject some or all animal products. Market research studies indicate that many younger individuals, who do not join groups such as the Vegetarian Society, give up animal foods in response to peer pressure and in an individualistic way. Dietary studies done in the past have shown that while 'vegetarian' diets provide more than adequate intakes of many nutrients, intakes of others (such as zinc and vitamin $\mathrm{B}_{12}$ ) can fall well below recommended levels (Bull \& Barber, 1984; Carlson et al. 1985; Freeland-Graves, 1988). Established vegetarian groups provide nutrition and health information to their members, but nonmembers may rely on the popular media and their friends for information about their nutritional needs and the problems (if any) of their new diet. In view of this, a study was undertaken of the diet and food choice of vegetarians in the London area in which an attempt was made to recruit some of the 'new' vegetarians as well as those within established vegetarian networks. The object of the study was to find out what vegetarians were eating and also to evaluate their knowledge and opinions about food, diet and health.

\footnotetext{
* Present address: The Wellcome Trust, The Wellcome Centre for Medical Science, 183 Euston Road, London NW1 2BE.
} 


\section{STUDY DESIGN AND METHODS}

Three groups were defined. Vegans avoid all animal products; lacto-ovo-vegetarians usually avoid all meat and fish; and demi-vegetarians usually avoid meat. It was expected that lacto-ovo-vegetarians would include 'traditional' vegetarians, vegans the most committed type, and demi-vegetarians the 'new', individualistic vegetarian, and that significant variations in risk of nutrient deficiency would arise from their different dietary patterns.

A non-random volunteer sample of 150 was sought, with equal numbers in each vegetarian group. The London area was chosen partly for logistic reasons but also because of its attraction for younger people and those with unorthodox lifestyle. Subjects were recruited through local radio, community events and centres such as a 'green fair', health food shops (which displayed posters), societies of vegetarians and vegans, and personal contacts. All subjects had elected to modify their diets as adults; those who had been brought up in a vegetarian lifestyle were excluded. This condition eliminated most members of mainstream religious groups who regularly avoid meat, but some adult converts to Buddhism were included.

All subjects were asked to complete a $3 \mathrm{~d}$ weighed dietary intake using a digital readout balance (Soehnle; $1 \mathrm{~kg} \times 1 \mathrm{~g}$ ); refusers $(n 6)$ were instructed in how to complete a $3 \mathrm{~d}$ diary with household measures. These two methods showed good agreement in a previous study (Schofield et al. 1987). Left-over food weights were recorded. In addition, a food frequency questionnaire and an extensive interview schedule on attitudes to diet, health and lifestyle were administered. Subjects were not weighed but were asked their latest body-weight. The questionnaires were tested in a pilot study of five subjects whose data were not included in the main study. All subjects were seen twice, sometimes in their workplace, but always on at least one occasion in their own home. In order to test for seasonal variations in intake, a $25 \%$ follow-up sub-sample completed a second weighed intake 6 months after the first.

After coding, the dietary data were analysed with in-house programs using the Ministry of Agriculture, Fisheries and Food (MAFF) computerized database, which contains over 5000 individual food codes. This had been specially developed for the recent dietary and nutritional survey of British adults (Gregory et al. 1990). It was based on McCance and Widdowson's The Composition of Foods (Paul \& Southgate, 1978; Paul et al. 1980; Tan et al. 1985) but also incorporated a large amount of unpublished MAFF data. Specialist vegetarian products were added to the database for the present study. Subjects who consumed composite dishes were asked to record recipe details, and the nutrient content of the dish was then calculated from the raw ingredients after allowing for likely fat or moisture losses or gains and after making standard adjustments for nutrient losses during cooking. In coding non-weighed food diaries, average portion sizes were calculated using Food Portion Sizes (Crawley, 1988). Non-starch polysaccharides (NSP) were defined by the method of Southgate (1978).

The calculation of the vitamin and mineral contents of $3 \mathrm{~d}$ records does not estimate individual intakes with sufficient precision to rank or correlate them. Only group means are presented here. The database takes account of cooking losses of heat-labile vitamins. Folic acid data in food composition tables are derived from a variety of analytical techniques (Paul \& Southgate, 1978), and intakes must, therefore, be interpreted with caution. Data on vitamin $B_{12}$ are also subject to considerable methodological problems (Herbert, 1988). However, the database included many recent analyses plus information from manufacturers on vitamin $\mathbf{B}_{12}$ supplements added to their products.

The output from the dietary calculations consisted of arithmetic mean daily weights of food groups consumed and intakes of energy and nutrients. Statistical analysis was done 
Table 1. Distribution by age, sex and vegetarian group of vegetarians who completed a dietary survey

\begin{tabular}{|c|c|c|c|c|c|c|c|}
\hline \multirow[b]{2}{*}{ Group } & \multirow[b]{2}{*}{ Sex } & \multicolumn{6}{|c|}{ Age range (years) } \\
\hline & & $<20$ & $21-30$ & $31-40$ & $41-60$ & $>60$ & All \\
\hline \multirow[t]{3}{*}{ Demi-vegetarian } & $\mathbf{M}$ & 0 & 4 & 6 & 2 & 1 & 13 \\
\hline & $\mathbf{F}$ & 0 & 9 & 8 & 5 & 2 & 24 \\
\hline & Both & 0 & 13 & 14 & 7 & 3 & 37 \\
\hline \multirow{3}{*}{$\begin{array}{l}\text { Lacto-ovo- } \\
\text { vegetarian }\end{array}$} & $\mathbf{M}$ & 0 & 9 & 2 & 3 & 2 & 16 \\
\hline & $\mathbf{F}$ & 1 & 13 & 13 & 3 & 3 & 36 \\
\hline & Both & 1 & 22 & 15 & 6 & 8 & 52 \\
\hline \multirow[t]{3}{*}{ Vegan } & $\mathbf{M}$ & 0 & 9 & 8 & 1 & 0 & 18 \\
\hline & $\mathrm{F}$ & 3 & 5 & 7 & 3 & 2 & 20 \\
\hline & Both & 3 & 14 & 15 & 4 & 2 & 38 \\
\hline \multirow[t]{3}{*}{ All } & $\mathbf{M}$ & 0 & 22 & 16 & 6 & 3 & 47 \\
\hline & $\mathrm{F}$ & 4 & 27 & 28 & 11 & 10 & 80 \\
\hline & Both & 4 & 49 & 44 & 17 & 13 & 127 \\
\hline
\end{tabular}

Demi-vegetarian, usually avoids meat; lacto-ovo-vegetarian, avoids all meat and fish; vegan, avoids all animal products.

using the SPSSPC + package. Distributions of intakes were checked for skewness by the Kolmogorov-Smirnov test (Siegel, 1956) and a lognormal transformation was applied where appropriate. Between-group comparisons were made using ANOVA, and comparisons between the main survey and the 6-month follow-up by paired $t$ test. These intakes are compared with data from a nationwide survey of adults in the UK (Gregory et al. 1990), taking social classes 1 and 2 as a comparison group because these classes predominated in the sample (see pp. 5-6). This is referred to subsequently as the 'nationwide sample'.

\section{RESULTS}

The follow-up survey showed no significant seasonal differences in intake of any nutrient, and the results are not presented here.

\section{The sample}

The number initially recruited was 137 ; the dietary part of the study was completed by 127 subjects of whom six kept non-weighed food diaries. Table 1 shows the distribution of these subjects by vegetarian group, sex, and age. Females (63\%) outnumbered males. The modal age-range was 21-30 years. The modal length of time as a vegetarian was shortest for vegans ( 1 year) followed by lacto-ovo-vegetarians ( 2 years) and demi-vegetarians (5-9 years). Older subjects were most likely to be lacto-ovo-vegetarians (Table 1). These variables were not significantly associated. Membership of any vegetarian or vegan society was highest among vegans (Table 7). Evidently it had been possible to recruit both new, unaffiliated, younger 'vegetarians' and older, more established and traditional 'vegetarians' into the study.

Membership of vegetarian group was assigned according to the subjects' self-description, and checked by the dietary records. Although the dietary analysis (Tables 3 and 7) shows intakes of dairy products and cholesterol by some vegans, this is due to use of commercial 
processed foods. Some vegans were more meticulous than others in checking these for animal products, and the database did not always distinguish vegan versions of processed foods.

The sample was predominantly from higher social classes, and well educated: $78 \%$ had at least one GCE/GCSE pass at 'A' level, and $51 \%$ had a degree or equivalent. Social classes $1+2$ (Office of Population Censuses and Surveys, 1980), comprised $58 \%$ of the sample. There were no significant between-group differences in education or social class. By contrast, in Greater London as a whole $7 \%$ have a higher educational qualification and $24 \%$ are members of social classes $1+2$.

The mean reported body-weights of demi-vegetarians, lacto-ovo-vegetarians, and vegans were $74 \cdot 7,69 \cdot 0$ and $64.4 \mathrm{~kg}$ (males) and $57 \cdot 9,59 \cdot 0$ and $55 \cdot 4 \mathrm{~kg}$ (females) respectively, with no significant between-group differences.

\section{Energy intakes}

All the mean energy intakes were close to the Department of Health (1991) recommended intakes for the UK (Tables 2 and 6). As expected, there was a highly significant effect of sex on energy intake, but there was no effect of vegetarian group. Compared with the nationwide sample, mean intakes of male vegetarians were lower by about $10 \%$, and those of women were slightly higher. The principal food group contributors $(\%)$ to energy were cereals (demi-vegetarians 32, lacto-ovo-vegetarians 34, vegans, 40), dairy products (demivegetarians 12, lacto-ovo-vegetarians 11) and fruit products (especially vegans, 11).

\section{Protein}

All mean protein intakes were above the UK recommendations, although lower than those in the nationwide sample (Tables 2 and 6). Cereals contributed $30-40 \%$ of protein, followed by dairy products (demi-vegetarians $20 \%$; lacto-ovo-vegetarians $23 \%$ ), soyabean products (vegans 10\%), and vegetables (all groups, 7-10\%).

\section{Carbohydrates, including NSP}

The significant effect of sex on all calculated carbohydrate intakes followed the pattern for energy, with no effect of vegetarian group (Table 2). Vegan women had the highest percentage energy from carbohydrate (55). There was no significant difference in the sugars: starches ratio between the vegetarians and the UK sample.

Total NSP intakes were significantly affected by both sex and vegetarian group (with no interaction), so that men and vegans had the higher intakes. NSP intakes in all groups were above the nationwide sample mean, and were about $80 \%$ higher in vegans. All mean intakes were above the dietary reference values (DRV) (Table 6) and above $25 \mathrm{~g} / \mathrm{d}$, the level recommended by the National Advisory Committee for Nutrition Education (NACNE; James, 1983). NSP intake expressed as $\mathrm{g} / \mathrm{MJ}$ showed no significant sex difference.

\section{Alcohol}

Reported intakes of alcoholic drinks were relatively low, with no significant between-group differences (Tables 2 and 7).

\section{Fats}

The mean total fat intakes and the percentage of energy from fat of the demi-vegetarians and lacto-ovo-vegetarians (Table 3) were similar to those of UK omnivores (Bingham et al. 1981; Carlson et al. 1985; Gregory et al. 1990). Those of the vegans were close to recommended averages, with females having significantly lower intakes than males. (Table 6). Demi-vegetarians had the highest fat intake, and in both non-vegan groups the mean 


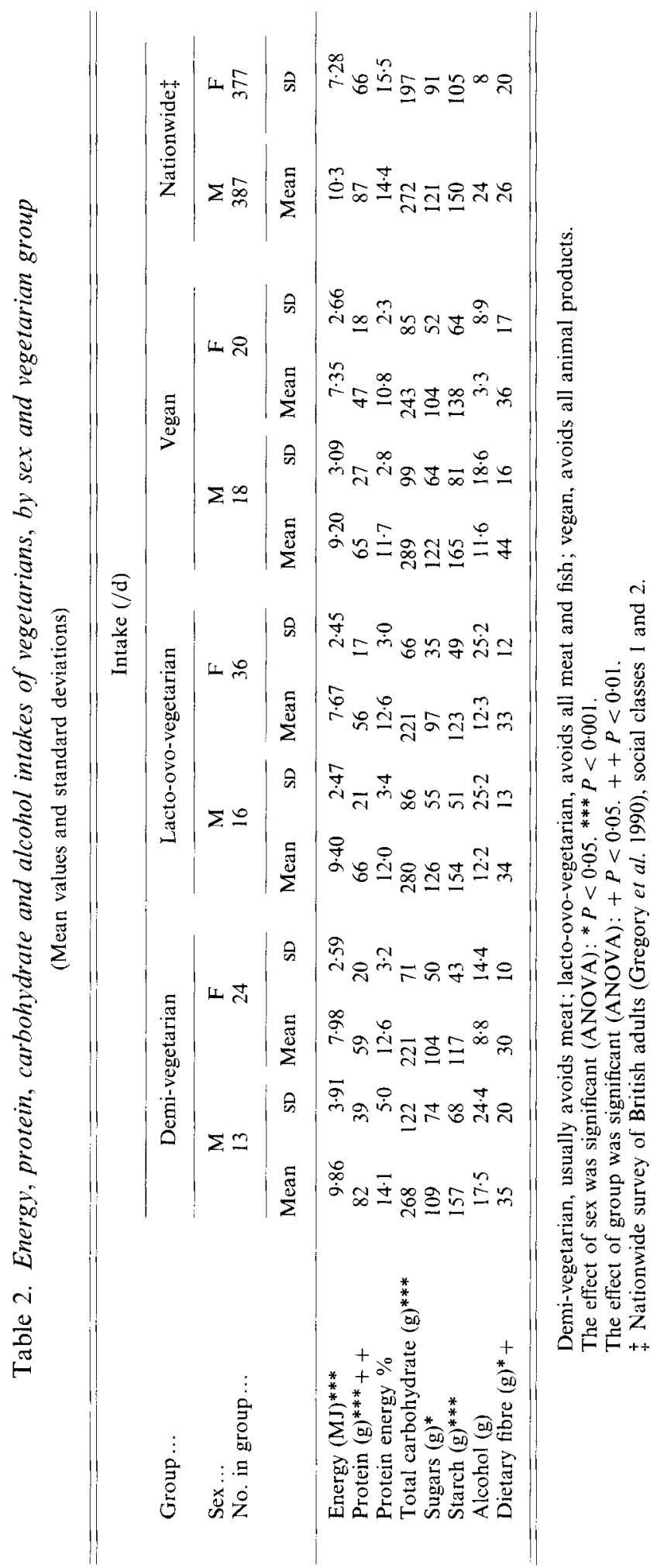


A. DRAPER AND OTHERS

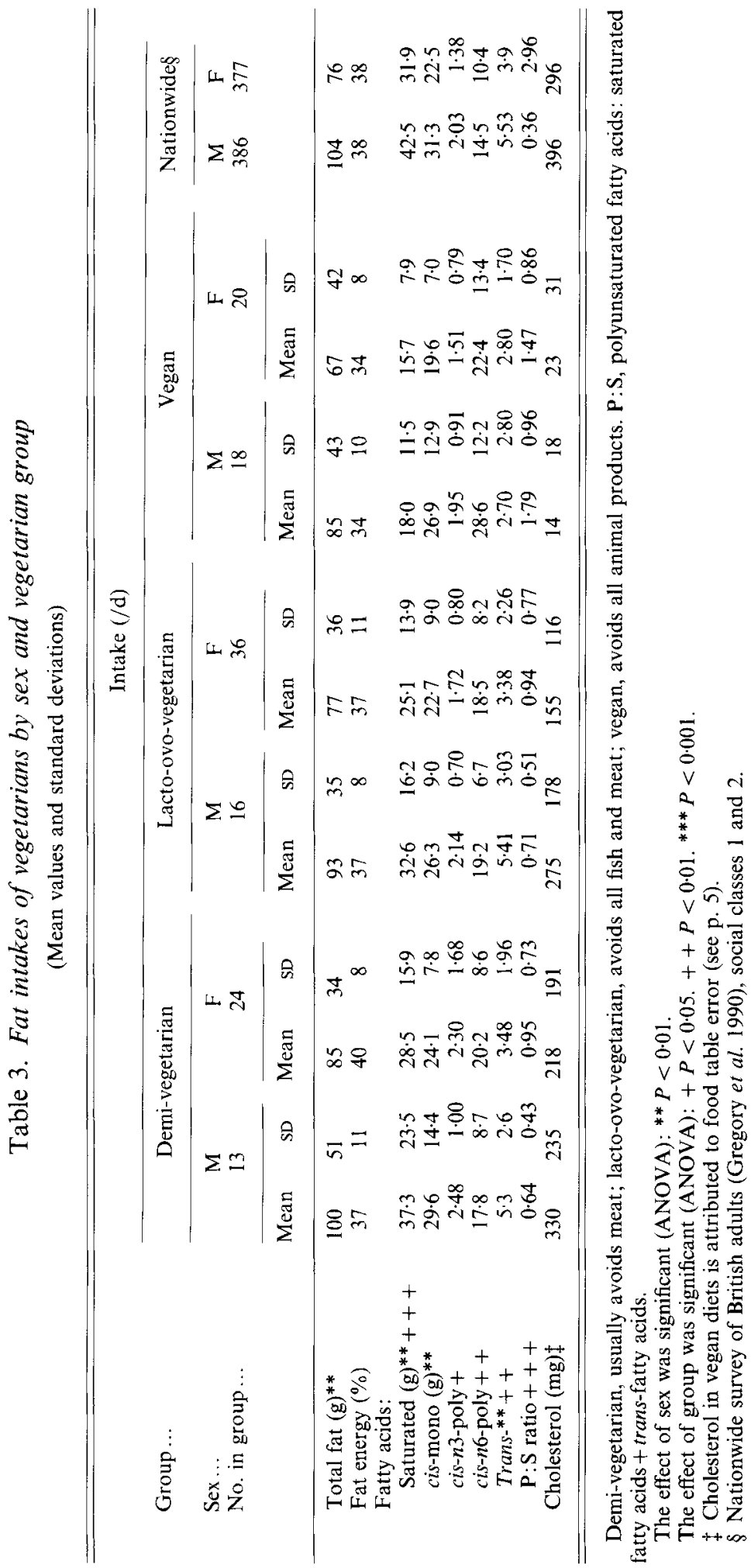


intake of males was above the recommended $33 \%$ of energy coming from fat. There was a downward trend in the percentage of energy coming from fat, from demi-vegetarians to vegans, but there was no significant effect of group on percentage energy from fat.

Saturated fatty acid intakes were significantly lower in vegans and in women, with no interaction (ANOVA). Total fats and monounsaturated fatty acids showed significant differences only between sexes (linked to energy intake) but polyunsaturated fatty acid intakes were higher in vegans, whose polyunsaturated:saturated fatty acid (P:S) ratios frequently exceeded 1 . Intakes of the $n-3$ and $n-6$ fatty acids showed significant inter-group differences, but no sex differences. The percentage energy derived from both saturated and polyunsaturated fatty acids was above recommended levels (Department of Health, 1991) in all groups, with the exception of saturated fatty acids in the vegan group. Compared with the nationwide sample, all groups' intakes of saturated fatty acids were lower, and of unsaturated fatty acids higher, with higher $\mathrm{P}: \mathrm{S}$ ratios. Vegan intakes were consistently the closest to, or most favourable in comparison with, current guidelines for the distribution of dietary fats. In summary, while only vegans had lower total fat intakes than those of omnivores, all groups had a more favourable $\mathrm{P}: \mathrm{S}$ ratio.

The major sources of fats were cereals and cereal products (demi-vegetarians $19 \%$, lactoovo-vegetarians $22 \%$, vegans $26 \%$ ) dairy products (demi-vegetarians $18 \%$, lacto-ovovegetarians $15 \%$ ), and vegetable fats and oils, including dressings on salads (all groups $15 \%)$. In the nationwide survey, meat and meat products were the highest source of fat, followed by cereals and cereal products. Only $5 \%$ of demi-vegetarians ate any oily fish during the survey.

\section{Minerals}

All mean calcium intakes exceeded the UK DRV, with the lowest values in vegans, who avoided dairy products (Table 4). After dairy foods, cereals and vegetables were the next most important sources of $\mathrm{Ca}$ (but the contribution of water was not estimated). Magnesium intakes were high, especially for vegans, and very variable. This was mainly due to variation in the consumption of soya-bean products. Tofu, a curd made from soya bean, is traditionally precipitated using nigari, the liquor remaining after extraction of sodium chloride from sea-water, which is rich in $\mathrm{Mg}$. Commercial tofu is precipitated using $\mathrm{Ca}$ salts. Iron intakes were also high, and intakes per $4.2 \mathrm{MJ}$ (1000 kcals) for females were higher than those for males. However, this is all non-haem-Fe. $\mathrm{Zn}$ intakes were similar in all groups, and close to the DRV. Cereals were the main source, followed by dairy products (demi-vegetarians and lacto-ovo-vegetarians). Copper intakes were high, and highly skewed, partly due to the Cu content $(17 \mathrm{mg} / \mathrm{kg})$ attributed to tofu in the food composition tables. More recent analytical data (Ministry of Agriculture, Fisheries and Food, personal communication), gives $2 \mathrm{mgCu} / \mathrm{kg}$ in tofu; so high $\mathrm{Cu}$ intakes may be a food table artifact. Iodine intakes were high in the two groups who ate fish, but vegans consumed only $50-70 \%$ of the DRV.

The $\mathrm{Fe}, \mathrm{Zn}, \mathrm{Mg}$, and $\mathrm{Cu}$ intakes of all three groups were above or similar to those of the UK nationwide sample (Gregory et al. 1990). Vegans were distinguished by lower Ca and I intakes.

\section{Fat-soluble vitamins}

Total retinol equivalent intakes were high in all groups, who all had high carotene intakes. (Table 5). Vitamin D intakes of demi- and lacto-ovo-vegetarians met the level defined by the Department of Health and Social Security (1979), being derived from animal products and fortified margarine (Table 6). Vegans had lower intakes, derived from dietary supplements and margarine. The assumption made by the Department of Health (1991) that adults can derive a sufficient amount of the vitamin from exposure to sunlight would 
A. DRAPER AND OTHERS

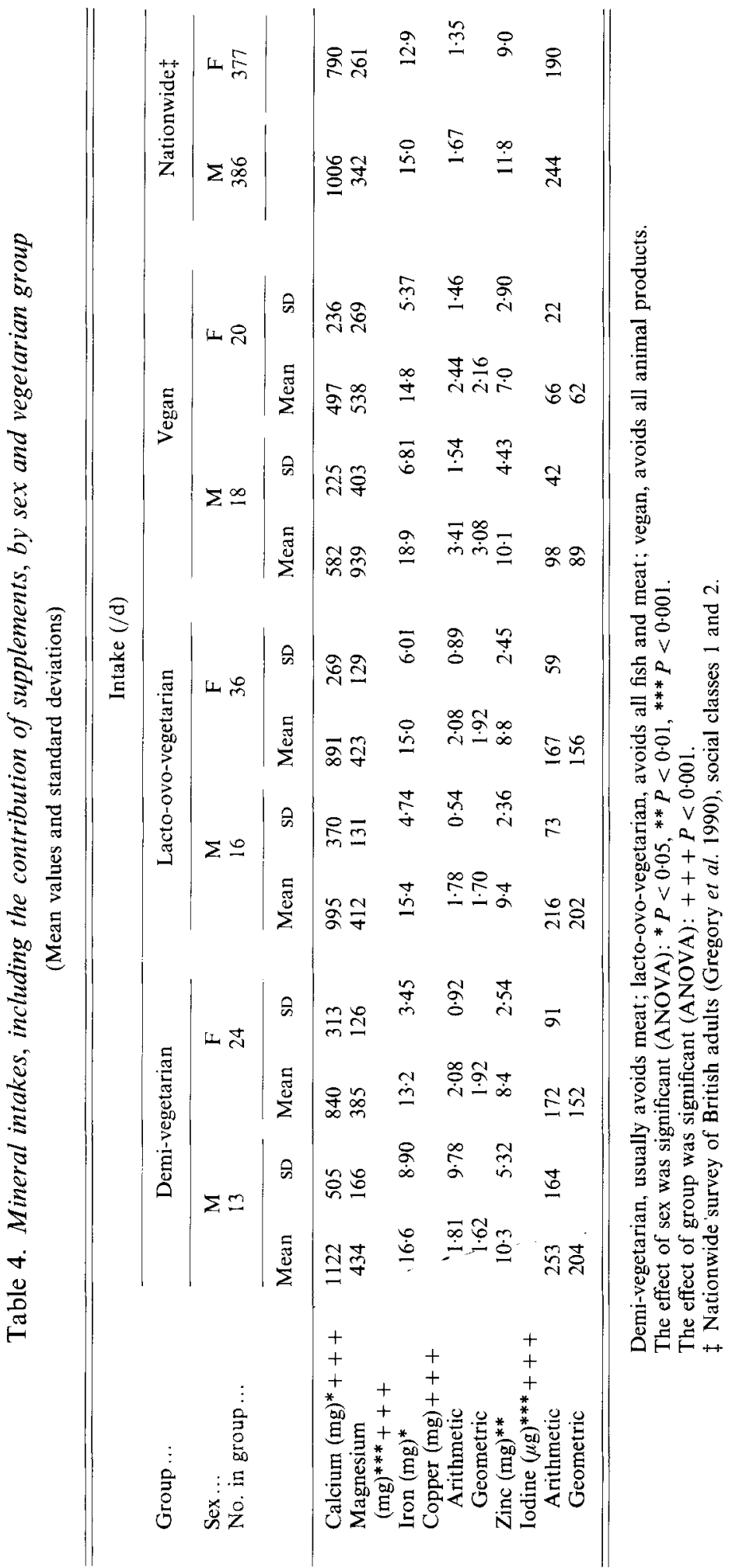


VEGETARIANS' DIETARY INTAKE

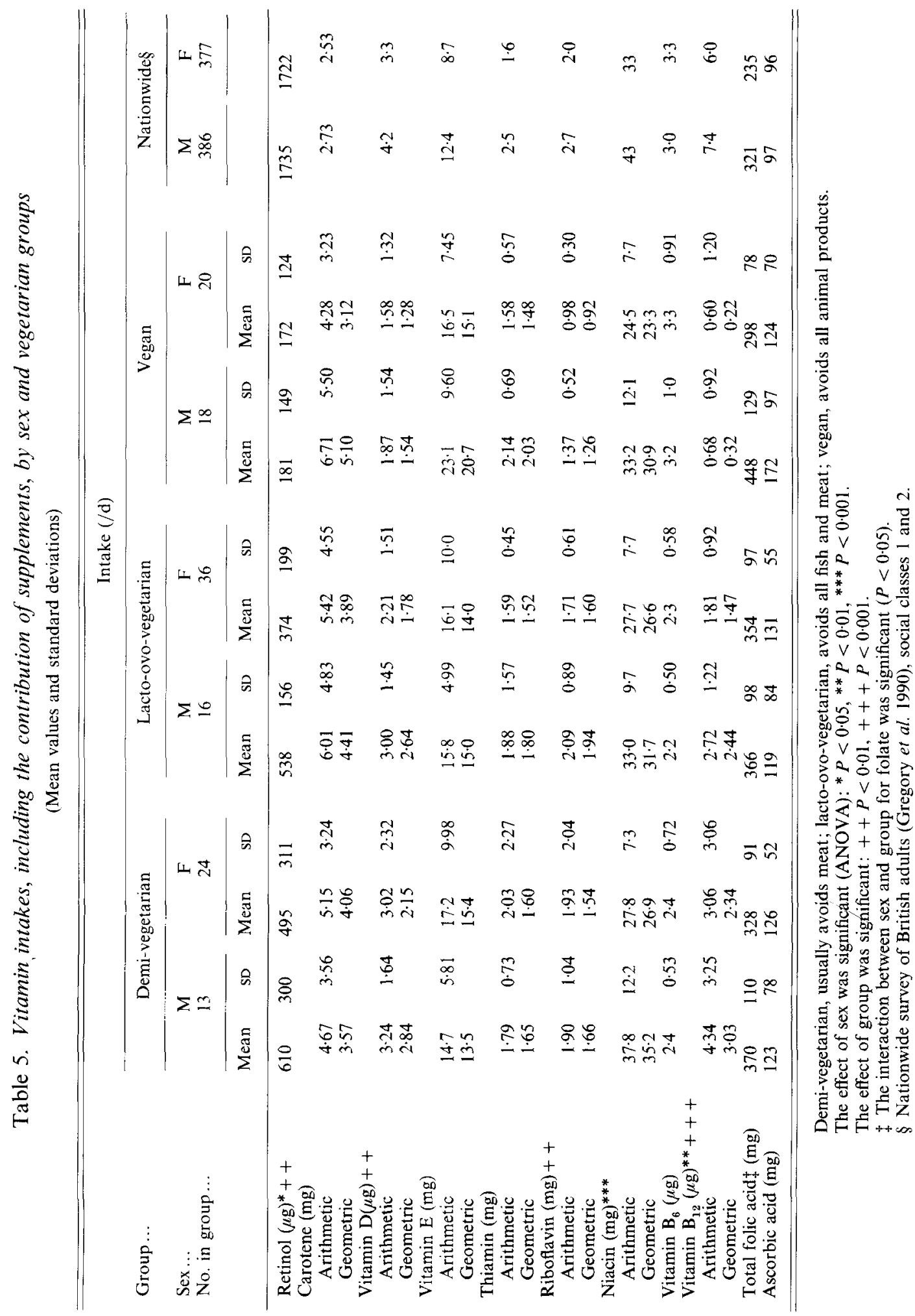


Table 6. Comparison of vegetarians' mean intakes of energy, non-starch polysaccharides (NSP) and selected nutrients with current recommendations and guidelines

\begin{tabular}{|c|c|c|c|c|c|c|c|c|}
\hline \multirow{3}{*}{$\begin{array}{l}\text { Group... } \\
\text { Sex... }\end{array}$} & \multicolumn{2}{|c|}{ Recommendation } & \multicolumn{6}{|c|}{$\begin{array}{l}\text { Percentage of mean recommendation } \\
\text { or upper limit of range }\end{array}$} \\
\hline & \multirow[b]{2}{*}{ M } & \multirow[b]{2}{*}{$\mathrm{F}$} & \multicolumn{2}{|c|}{$\begin{array}{l}\text { Demi- } \\
\text { vegetarian }\end{array}$} & \multicolumn{2}{|c|}{$\begin{array}{l}\text { Lacto-ovo- } \\
\text { vegetarian }\end{array}$} & \multicolumn{2}{|c|}{ Vegan } \\
\hline & & & M & $\mathbf{F}$ & $\mathbf{M}$ & $\mathrm{F}$ & $\mathbf{M}$ & $\mathrm{F}$ \\
\hline Energy $(\mathrm{MJ})^{* \dagger}$ & $10 \cdot 6$ & $8 \cdot 1$ & 93 & 98 & 89 & 95 & 87 & 91 \\
\hline Protein $(\mathrm{g})^{* \dagger}$ & $53 \cdot 3$ & $46 \cdot 5$ & 153 & 127 & 124 & 120 & 123 & 101 \\
\hline Fat energy $(\%) \dagger$ & 33 & 33 & 112 & 121 & 112 & 112 & 103 & 103 \\
\hline SFA (\% energy) ${ }^{*}$ & 10 & 10 & 140 & 134 & 130 & 121 & 72 & 80 \\
\hline PUFA (\% energy)* & 6 & 6 & 125 & 176 & 141 & 162 & 204 & 202 \\
\hline NSP $(g)$ & 18 & 18 & 194 & 167 & 189 & 183 & 244 & 200 \\
\hline Copper $(\mathrm{mg})^{*}$ & $1 \cdot 2$ & $1 \cdot 2$ & 151 & 173 & 148 & 173 & 284 & 203 \\
\hline $\operatorname{Zinc}(\mathrm{mg})^{*}$ & $9 \cdot 5$ & $7 \cdot 0$ & 108 & 119 & 99 & 126 & 106 & 100 \\
\hline Iodine $(\mu \mathrm{g})^{*}$ & 140 & 140 & 181 & 123 & 154 & 119 & 70 & 47 \\
\hline Vitamin $\mathbf{D}(\mu \mathrm{g}) \ddagger$ & $2 \cdot 5$ & $2 \cdot 5$ & 128 & 120 & 120 & 88 & 75 & 63 \\
\hline Ribotlavin (mg)* & $1 \cdot 3$ & $1 \cdot 1$ & 146 & 175 & 161 & 155 & 105 & 89 \\
\hline Vitamin $\mathbf{B}_{12}(\mu \mathrm{g}) \S$ & 1.0 & $1 \cdot 0$ & 430 & 310 & 270 & 180 & 68 & 60 \\
\hline
\end{tabular}

Demi-vegetarian, usually avoids meat; lacto-ovo-vegetarian, avoids all fish and meat; vegan, avoids all animal products.

SFA, saturated fatty acids; PUFA, polyunsaturated fatty acids.

* Department of Health (1991).

$\uparrow$ Age 19-50 years.

$\ddagger$ Department of Health and Social Security (1979).

$\$$ Food and Agriculture Organization (1988).

apply to all these groups. All vitamin $\mathrm{E}$ intakes were high, being derived from grains and vegetable oils.

Mean intakes of carotene and vitamin $\mathrm{E}$ were much higher than those of the nationwide sample (Gregory et al. 1990). All groups had lower retinol intakes (the small retinol intake attributed to vegans is derived from fortified margarine). Demi- and lacto-ovo-vegetarians had mean vitamin $D$ intakes about $25 \%$ lower than the nationwide sample, and those of vegans less than half those of the nationwide sample.

\section{Water-soluble vitamins}

Mean intakes of thiamin, niacin, pyridoxine, folic acid and ascorbic acid were above the UK DRV in all groups, reflecting high plant food intakes (Tables 5 and 6). The mean riboflavin intake of vegans, who avoided milk products, was below the UK DRV.

Vitamin $B_{12}$ intakes were low in all groups, and especially so in vegans. Recommended daily allowances (RDA) for vitamin $\mathrm{B}_{12}$ have decreased steadily since they first appeared; in 1987 the World Health Organization revised their estimate to $1 \mu \mathrm{g} / \mathrm{d}$ (Food and Agriculture Organization, 1988). The UK DRV is set at $1.5 \mu \mathrm{g} / \mathrm{d}$. Over the $3 \mathrm{~d}$ of survey, six of thirty-eight vegans recorded no source of vitamin $B_{12}$, and their range of intakes was $0-5.66 \mu \mathrm{g} / \mathrm{d}$.

Compared with the nationwide sample, the demi- and lacto-ovo-vegetarians had higher mean intakes of ascorbic acid, similar intakes of folic acid, and lower intakes of other B vitamins. The vegans compared similarly except that riboflavin and vitamin $B_{12}$ were markedly lower than in the nationwide sample. 


\section{Food group intakes}

The classification of food groups leads to problems where multi-ingredient foods are concerned. For example, coleslaw bought from a supermarket is classed as 'salad', but contains some oil and milk solids. Food groups, therefore, are only very broad definitions based on the predominant food in a mixture. There were significant differences ( $\chi^{2}$ test) in the numbers consuming soya-bean products and sugars (Table 7). Vegans had a higher frequency for soya-bean products and a lower frequency for sugars. Twelve $(31 \%)$ vegans appeared to consume small amounts of animal-milk products during the $3 \mathrm{~d}$ of survey; this is attributable to consumption of commercial processed foods. There was a marginally significant difference $(P=0.06)$ between the mean cereal group intakes, with vegans consuming the most; no other group means showed significant differences. The range of food group intakes was large, and intake distributions were skewed, especially of legumes and their products.

Cereals (including wheat, rice, maize, and oats) emerged as the staple food group, contributing between 30 and $40 \%$ of energy and macronutrients. In the nationwide sample, cereals contributed $30 \%$ energy, with meat and meat products as the next highest contributing group. Although legumes, nuts and fruits are commonly regarded as the mainstay of a vegetarian diet, it was cereals and vegetables (including salads), and milk for those who used it, which contributed most to micronutrient intakes.

The main food group sources of vitamin $B_{12}$, apart from supplements, were yeastcontaining foods (baked cereal products and alcoholic drinks), manufactured foods containing supplementary vitamin $\mathrm{B}_{12}$, and a few fermented soya-bean and vegetable products, which supplied the vegans. Even these values may be overestimates; Herbert (1988) has pointed out that manufacturers' estimates of the vitamin $\mathrm{B}_{12}$ content of foods are liable to be in error, due to confusion between the vitamin and its non-active analogues.

Most $(95 \%)$ of vegans used sea salt, seaweed, or Vecon, a yeast-based food containing seaweed powder. Use frequencies varied between 'daily' ( $<10 \%$ of vegans) and 'less than monthly' $(<10 \%)$, with 'one to four times/month' as the modal frequency $(30-40 \%)$.

\section{Use of dietary supplements}

When asked 'Do you feel that you get all the vitamins you need from food?', $48.6 \%$ of demi-vegetarians, $57 \cdot 4 \%$ of lacto-ovo-vegetarians, and $67.4 \%$ of vegans answered 'Yes'. Besides vitamin and mineral supplements, the survey subjects took a range of some twenty supplements including ginseng, royal jelly, garlic and kelp. Only eight took yeast tablets (another vitamin $\mathrm{B}_{12}$ source). Most had tried some form of 'alternative' medicine, and $71 \%$ were currently using some 'alternative' remedies (mostly homeopathic or herbal).

The subjects were questioned about their use of dietary supplements; $49 \%$ of demivegetarians, $41 \%$ of lacto-ovo-vegetarians and $54 \%$ of vegans claimed to use them regularly or sometimes. The most popular supplement was multi-vitamins $(27 \%$ of all subjects); $22 \%$ took some type of mineral ( $\mathrm{Zn}, \mathrm{Ca}$, selenium and multi-minerals). On the $3 \mathrm{~d}$ of the survey, $25 \%$ of the subjects took supplements.

Table 8 shows the mean amounts of additional nutrients obtained by supplement-takers. The match between nutrients whose intakes were below the DRV and nutrients supplied by the supplements was not close. Supplement-taking vegans were adding to their diets, at or above $10 \%$ of the DRV, three nutrients (I, riboflavin, vitamin $B_{12}$ ) whose intakes fell below the DRV, and six ( $\mathrm{Zn}$, retinol, vitamin $\mathrm{D}$, vitamin $\mathrm{E}$, thiamin, and pyridoxine) which did not. Supplementation with retinol was particularly high and inappropriate, while more I and vitamin $B_{12}$ might have been beneficial. 
Table 7. Intake by vegetarians of major food groups, sexes combined $\dagger$, consumers only

\begin{tabular}{|c|c|c|c|c|c|c|c|c|}
\hline \multirow{3}{*}{ Group ... } & \multicolumn{6}{|c|}{ Intake $(\mathrm{g} / \mathrm{d})$} & \multirow{2}{*}{\multicolumn{2}{|c|}{$\begin{array}{c}\text { Statistical } \\
\text { significance }\end{array}$}} \\
\hline & \multicolumn{2}{|c|}{$\mathrm{D}$} & \multicolumn{2}{|c|}{$\mathrm{L}$} & \multicolumn{2}{|c|}{ V } & & \\
\hline & Mean & $n$ & Mean & $n$ & Mean & $n$ & ANOVA & $x^{2}$ \\
\hline Cereals & 266 & 37 & 264 & 52 & 340 & 38 & & \\
\hline Potatoes & 90 & 30 & 109 & 39 & 102 & 20 & & \\
\hline Lentils & 52 & 7 & 101 & 9 & 89 & 10 & & \\
\hline Bean & 88 & 19 & 94 & 33 & 96 & 22 & & \\
\hline Tofu & 76 & 4 & 40 & 11 & 59 & 12 & & $* *$ \\
\hline Other soya-bean products & 100 & 5 & 110 & 7 & 185 & 24 & $* *$ & $* * *$ \\
\hline Salad & 91 & 29 & 102 & 41 & 117 & 29 & $* * *$ & \\
\hline Other vegetables & 219 & 3 & 274 & 51 & 293 & 37 & & \\
\hline Nuts & 35 & 22 & 33 & 29 & 39 & 22 & & \\
\hline Fruit & 203 & 35 & 214 & 51 & 322 & 35 & & \\
\hline Fruit juice & 185 & 21 & 159 & 33 & 187 & 21 & & \\
\hline Vegetarian dishes & 58 & 10 & 64 & 17 & 57 & 7 & & \\
\hline Fats & 18 & 31 & 17 & 48 & 19 & 23 & & \\
\hline Sugar products & 33 & 29 & 35 & 44 & 26 & 19 & $* *$ & ** \\
\hline Alcoholic drinks & 199 & 19 & 204 & 28 & 127 & 12 & & \\
\hline Milk§ & 203 & 32 & 214 & 49 & 13 & 8 & & \\
\hline Egg§ & 50 & 19 & 48 & 19 & & - & & \\
\hline Fish & 105 & 18 & 4 & 1 & & - & & \\
\hline Meat & 44 & 7 & & - & & - & & \\
\hline Dietary supplements & 3.4 & 8 & 1.7 & 14 & $4 \cdot 1$ & 6 & & \\
\hline
\end{tabular}

D, demi-vegetarians (usually avoid meat); L, lacto-ovo-vegetarian (avoid all fish and meat); V, vegan (avoid all animal products).

$\uparrow$ Sexes combined because of small numbers consuming some foods.

$\ddagger$ Oneway ANOVA of group means; $\chi^{2}$ for frequency of those consuming the food, by vegetarian group.

${ }^{* *} P<0.01,{ }^{* * *} P<0.001$.

$\S$ No significant differences between groups $\mathrm{D}$ and $\mathrm{L}$.

Table 8. Mean amounts of micronutrients derived from dietary supplements, compared with $10 \%$ of the dietary reference values $(D R V)^{*}$, by vegetarian group, sexes combined

\begin{tabular}{|c|c|c|c|c|}
\hline & $\begin{array}{c}\text { Demi- } \\
\text { vegetarian }\end{array}$ & $\begin{array}{l}\text { Lacto-ovo- } \\
\text { vegetarian }\end{array}$ & Vegan & $10 \%$ of DRV \\
\hline Zinc (mg) & $0 \cdot 37$ & $0 \cdot 15$ & 0.78 & 0.95 \\
\hline Iodine $(\mu \mathrm{g})$ & 0 & 0 & $15 \cdot 6$ & 14 \\
\hline Retinol equiv & 69 & 676 & 700 & 70 \\
\hline Vitamin $\mathrm{D}^{\dagger}(\mu \mathrm{g})$ & 0.42 & 0.37 & 0.37 & 0.25 \\
\hline Vitamin $E(\mathrm{mg})$ & 48 & $3 \cdot 3$ & $4 \cdot 1$ & 0.4 \\
\hline Thiamin (mg) & $1 \cdot 48$ & $0-26$ & 0.21 & 0.09 \\
\hline Riboflavin (mg) & 0.69 & $0 \cdot 30$ & 0.25 & $0-13$ \\
\hline Pyridoxine $(\mu \mathrm{g})$ & $1 \cdot 11$ & 0.74 & 0.1 & $0 \cdot 14$ \\
\hline Vitamin $\mathrm{B}_{1 \mathrm{~g}}+(\mu \mathrm{g})$ & $0 \cdot 32$ & 0.26 & 0.25 & 0.1 \\
\hline $\begin{array}{l}\text { No. taking supplements } \\
\text { during survey }\end{array}$ & 7 & 14 & 9 & \\
\hline
\end{tabular}

Demi-vegetarian, usually avoids meat; lacto-ovo-vegetarian, avoids all fish and meat; vegan, avoids all animal products.

* Department of Health (1991).

$\dagger$ Department of Health and Social Security (1979).

+ Food and Agriculture Organization (1988). 
Table 9. Frequency $(\%)$ of responses to questions about lifestyle and commitment to diet by vegetarian groups

(Values in parentheses are percentage of total in each group)

\begin{tabular}{|c|c|c|c|}
\hline & $\begin{array}{l}\text { Demi- } \\
\text { vegetarian } \\
\text { (D) }\end{array}$ & $\begin{array}{l}\text { Lacto-ovo- } \\
\text { vegetarian } \\
\text { (L) }\end{array}$ & $\begin{array}{l}\text { Vegan } \\
\text { (V) }\end{array}$ \\
\hline $\begin{array}{l}\text { Has diet type changed? } \\
\text { No } \\
\text { Previously D } \\
\text { Previously L } \\
\text { Previously V }\end{array}$ & $\begin{array}{l}29(78) \\
-1 \\
6(16) \\
2(5)\end{array}$ & $\begin{array}{r}44(81) \\
8(15) \\
\frac{-}{2(4)}\end{array}$ & $\begin{array}{r}5(12) \\
1](23) \\
30(65) \\
-\end{array}$ \\
\hline $\begin{array}{l}\text { Membership of relevant organ } \\
\text { None } \\
\text { Vegetarian/vegan } \\
\text { Other* }\end{array}$ & $\begin{array}{c}26(70) \\
0 \\
11(30)\end{array}$ & $\begin{array}{l}25(46) \\
15(28) \\
14(26)\end{array}$ & $\begin{array}{l}10(22) \\
26(56) \\
10(22)\end{array}$ \\
\hline $\begin{array}{l}\text { Avoid animal-related products } \\
\text { Leather } \\
\text { Cosmetics }\end{array}$ & $\begin{array}{l}16(35) \\
25(68)\end{array}$ & $\begin{array}{l}43(80) \\
44(81)\end{array}$ & $\begin{array}{l}36(97) \\
44(96)\end{array}$ \\
\hline $\begin{array}{l}\text { Expression of opinion on diet } \\
\text { Always refuse meat } \\
\text { Attempt to spread opinions }\end{array}$ & $\begin{array}{l}20(54) \\
17(46)\end{array}$ & $\begin{array}{l}51(94) \\
29(54)\end{array}$ & $\begin{array}{l}45(98) \\
37(80)\end{array}$ \\
\hline$n$ & 37 & 54 & 46 \\
\hline
\end{tabular}

Demi-vegetarian, usually avoids meat; lacto-ovo-vegetarian, avoids all fish and meat; vegan, avoids all animal products.

* Health club, ecology group etc.

\section{Other effects on intake}

There was no significant effect on any food group or nutrient intake of length of time as a vegetarian, or age, or membership of a vegetarian society.

\section{Lifestyle}

The majority had adhered to their present diet for less than 5 years. Lacto-ovo-vegetarians, however, had a second peak at 15 years or more, while vegans all fell below the 15 -year mark. This is partly explained by Table 9 , which shows that most vegans had adopted lessrestricted diets at first. About $21 \%$ of demi-vegetarians had retreated from being lacto-ovovegetarians or vegans. However, taking the whole sample, $82 \%$ had either not changed their diet or had progressed to a more restricted one. Demi-vegetarians were the least likely to join relevant organizations, to avoid non-food animal-related products, to proselytize, or to refuse meat in a social situation. Vegans were the most committed, as judged by these indicators, and lacto-ovo-vegetarians held a middle position. There were clear differences among the groups in their adoption of a consistent lifestyle.

\section{DISCUSSION}

\section{Characteristics of the groups}

Vegans are committed avoiders of all animal products, with a consistent lifestyle and a tendency to join up with like-minded others. Lacto-ovo-vegetarians include the older vegetarians, whose commitment predates the present new wave of interest in animal rights or health, or both, and some of whom are likely to end up as vegans. Demi-vegetarians are more heterogeneous, containing some who are experimenting with the avoidance of animal 
foods and may move on to become lacto-ovo-vegetarians or vegans, with others who have moved back from those groups. They are the least likely to identify with vegetarian groups or to persuade others to adopt their views. Despite the differences between the groups, there is only one major dietary difference other than those following directly from the reduction of animal foods. That is, the high consumption of soya-bean products by some vegans, for whom it fills the dietary niche generally occupied by milk.

\section{Fats and other energy sources}

The fact that energy intakes were close to the Department of Health, UK, recommendations is no surprise. The mean intakes are in line with those recommended by the World Health Organization (1985) for adults expending energy at the rate of 1.6 times basal metabolic rate: that is, engaged in light to moderate activities. They are also similar to those recorded in recent surveys of both vegetarians and omnivores (Burr et al. 1981; Bull \& Barber, 1984; Carlson et al. 1985; Gregory et al. 1990). There may have been some change over time in this; Hardinge \& Stare (1954) found the intakes of vegans to be lower than those of omnivores in the 1950s. It is also no surprise that percentage protein energy was consistently above the requirement level, given the cereal base of the diets.

Fat contributed $34-40 \%$ to energy in different groups; only vegans came close to the $33 \%$ range recommended by the Department of Health (1991). Roshanai \& Saunders (1984) found a similar value for female vegans. Avoidance of all animal fats makes relatively little difference to total fat intakes and to the percentage of energy derived from fat. The $\mathrm{P}: \mathrm{S}$ ratio showed much greater differences, with vegans having values greater than 1. All groups considerably exceeded the Department of Health and Social Security (1984) and Department of Health (1991) recommendations on polyunsaturated fatty acids and $\mathrm{P}: \mathrm{S}$ ratio. The relatively high intakes of the $n-3$ and $n-6$ fatty acids are explained by high intakes of cereals and vegetable oils. Of those demi-vegetarians who ate fish during the survey, only about one-third ate oily fish, which is now considered to have some beneficial effects on mortality from coronary disease (Burr et al. 1989).

NSP intakes were significantly higher in vegans, who consumed more cereals and legumes than the others. NSP intakes of all groups were above the NACNE recommendation (James, 1983) and above the nationwide survey intakes.

In many respects the dietary analysis of the intakes of the two non-vegan groups showed them to be similar to UK omnivores. Only NSP and the P:S ratio really distinguished them. It is clear that in surveys of 'vegetarians', it is vegans who must be analysed separately, given their very different pattern of nutrient intakes. The vegan diet stands out as lower in energy and saturated fat, and higher in polyunsaturated fat and NSP than the others.

Although lacto-ovo-vegetarians avoided meat and fish, and demi-vegetarians ate both in small amounts, their percentage of energy coming from fat showed little difference from that of the nationwide sample. Clearly avoidance of meat alone does not lead to a significant reduction in fat intake. This point is not generally understood; many people believe that they can reduce their fat intake simply by avoiding meat fats.

\section{$\mathrm{Ca}, \mathrm{Mg}$ and $\mathrm{Zn}$}

The effect of vegetarian high-NSP diets on mineral absorption has been widely discussed. Kelsay et al. (1988) carried out mineral balances on vegetarians and concluded that there was no significant effect of a high-NSP high-carbohydrate diet on mineral utilization (even though the vegetarians had negative Mn balances). Kies (1988) has shown that a reduction in the fat content of a diet from 400 to $300 \mathrm{~g} / \mathrm{kg}$ reduces the absorption of $\mathrm{Ca}$ and $\mathrm{Zn}$. The combined effect of a high-NSP low-fat diet on $\mathrm{Zn}$ absorption was to reduce apparent absorption from $6 \%$ to $2 \%$. All our groups had high $\mathrm{Mg}$ intakes; demi- and lacto-ovovegetarians had $\mathrm{Ca}$ intakes well above the DRV, and vegans were close to it. There is little 
reason to suppose that they needed extra $\mathrm{Ca}$. $\mathrm{Zn}$ intakes were slightly lower than those in the nationwide sample, and close to the DRV. Lewis \& Buss (1988) found that meat and meat products account for $34 \%$ of $\mathrm{Zn}$ in the UK diet. It has been suggested that deficiencies might occur, especially with vegan diets, since some vegetarians have lowered plasma levels of $\mathrm{Zn}$ (Freeland-Graves et al. 1980), and reduced taste acuity, a sign of possible sub-clinical Zn deficiency (Freeland-Graves, 1988). The present study does not provide any basis for recommending $\mathrm{Zn}$ supplements.

\section{$\mathrm{Fe}$ and $\mathrm{Cu}$}

Kies (1988) claimed that reduction in dietary fat content reduced $\mathrm{Fe}$ absorption in vegetarians; Helman \& Darnton-Hill (1987) and Reddy \& Sanders (1990) have found lower plasma ferritin in vegetarians than omnivores. Other workers have suggested that a high intake of ascorbic acid may compensate in the case of Fe absorption, and have found no evidence of anaemia in long-term vegetarian women (Anderson et al. 1981). It may be that 'new' vegetarians show a transient effect of their dietary change on Fe status and that, in the long-term, adjustments in absorption restore mineral balance. In our sample, $18 \%$ had been a vegetarian for 1 year or less. $\mathrm{Cu}$ intakes seemed adequate in all groups.

\section{$I$}

The main sources of I in the UK diet are milk and dairy products, hence the very low intakes of vegans in spite of their use of sea-foods such as salt and seaweeds. There appears to be no evidence either for or against any functional effect of the low I intakes of vegans, and this nutrient needs further investigation.

\section{Fat-soluble vitamins}

All groups had high vitamin $\mathrm{E}$ intakes, and adequate vitamin $\mathrm{A}$ intakes when carotene was included. Only vegans had low vitamin D intakes. Although adults are expected to obtain much of their vitamin D through dermal synthesis, Millet et al. (1989) found 'deficient' concentrations of plasma 25 -hydroxycholecalciferol in $38 \%$ of their vegetarian subjects (who were not sub-classified). This is surprising in view of the capacity for dermal synthesis; but it is possible that in temperate climates during winter vegans may become temporarily depleted of the vitamin. Further studies are needed, especially of children.

\section{Vitamin $B_{12}$}

Some of this vitamin can be obtained through various kinds of contamination (Herbert, 1988), and manufacturers are increasingly adding it to their products (MAFF, personal communication); but the vegans' intakes found in our survey were extremely low. There is sufficient evidence for signs of deficiency in long-term vegans to establish the need for some additional source (Dwyer, 1988; Millet et al. 1989; Reddy \& Sanders, 1990).

\section{Other water-soluble vitamins}

The mean vitamin intakes of demi- and lacto-ovo-vegetarians were adequate, and in many cases extremely high. Cereals and legumes contributed $B$ vitamins other than vitamin $B_{12}$, and in addition milk was a good source of riboflavin as well as of fat-soluble vitamins. The main differences between the diets of vegans and those of the rest were in riboflavin, where the mean intakes were below the DRV.

\section{A case for supplements?}

Although a number of mean nutrient intakes were below current DRV, this alone does not imply clinical deficiency. The DRV is set at a level which allows for individual variation in requirement, and adds certain safety factors. Increasing likelihood of deficiency states 
accompanies decreasing intakes (National Academy of Science/National Research Council, 1986). A case for supplementation can only be made if there is some evidence of signs of clinical or sub-clinical deficiency, as well as 'low' dietary intakes.

There is no obvious needs for supplementation of the diets of those who only avoid meat or fish, or both. Vegans presented a different dietary picture. Reddy \& Sanders (1990), from a haematological study, state that vegetarians need to ensure that their intakes of Fe and vitamin $B_{12}$ are adequate. From our findings and from the literature, we conclude that there is a clear case for vegans to increase their intake of vitamin $B_{12}$, also probably of riboflavin, and that research is needed on the I status of vegans. The vegans who took supplements were using a mix of nutrients which they did and did not need, and were not taking I or vitamin $B_{12}$ in amounts sufficient to raise their mean intake to the DRV.

It is not clear why some subjects took supplements while others did not; this could not be explained by their age-group, or length of time as a vegetarian. The percentage doing so (25) during our survey was higher than in the general population (10; Gregory et al. 1990). As a group the vegetarians preferred unorthodox types of medical regimen, and expressed a preference for managing their own health (Draper et al. 1990). Worsley \& Crawford (1988), studying the use of supplements in the general population of Adelaide, found that supplement-takers were more likely to lead active and even stressful lives, and to have non-conformist attitudes. We cannot comment on the former, and would regard most of our subjects as non-conformist, to the extent that they follow minority dietary practices. Sanders (1988) reported that the majority of vegan parents accepted the need for some dietary supplementation for their children, but did not state how many used one themselves.

Two-thirds $(67 \%)$ of the vegans in the present study believed that their food could supply all necessary vitamins. Vegetarian and vegan literature does present the need for vitamin supplements, but only $54 \%$ of our vegan subjects were members of a society which might supply such information. The findings from the present and other studies suggest a need for dietary supplementation at two stages in an adult vegetarian career. The 'new' vegetarian, who has recently given up some or all animal products, may go into negative mineral balance. If mineral absorption mechanisms need time to adjust to reduced intake of minerals (especially haem-Fe), and increased NSP then a modest supplement might ease this transition. $\mathrm{Fe}, \mathrm{Zn}$ and $\mathrm{Ca}$ would be affected. The vegetarian who progresses to veganism certainly requires additional vitamin $B_{12}$, and $I$ and riboflavin are to be recommended as well. Nutrient supplements recommended for adults are also needed by children receiving similar diets, and in addition a dietary vitamin D intake is considered essential for children (Department of Health, 1991).

The authors thank the Ministry of Agriculture, Fisheries and Food for funding, and the survey subjects for their consistent cooperation.

\section{REFERENCES}

Anderson, B. M., Gibson, R. S. \& Sabry, J. H. (1981). The iron and zinc status of long-term vegetarian women. American Journal of Clinical Nutrition 34, 1042-1048.

Bingham, S., McNeil, N. I. \& Cummings, J. H. (1981). The diet of individuals: a study of a randomly-chosen cross-section of British adults in a Cambridgeshire village. British Journal of Nutrition 45, 23-35.

Bull, N. L. \& Barber, S. A. (1984). Food and nutrient intake of vegetarians in Britain. Human Nutrition: Applied Nutrition 38A, 288-293.

Burr, M. L., Bates, C. J., Fehily, A. \& St Leger, A. S. (1981). Plasma cholesterol and blood pressure in vegetarians. Journal of Human Nutrition 35, 437-451.

Burr, M. L., Fehily, A. M., Gilbert, J. F., Rogers, S., Holiday, R., Sweetman, P., Elwood, P. C. \& Deadman, N. M. (1989). Effects of changes in fat, fish and fibre intakes on death and myocardial reinfarction: diet and reinfarction trial (DART). Lancet ii 757-761. 
Carlson, E., Kipps, M., Lockie, A. \& Thomson, J. (1985). A comparative evaluation of vegan, vegetarian and omnivore diets. Journal of Plant Foods 6, 89-100.

Crawley, H. (1988). Food Portion Sizes. London: H.M. Stationery Office.

Department of Health (1991). Dietary Reference Values for Food Energy and Nutrients for the United Kingdom. Report on Health and Social Subjects no. 41. London: H.M. Stationery Office.

Department of Health and Social Security (1979). Recommended Daily Amounts of Food Energy and Nutrients for Groups of People in the United Kingdom. Reports on Health and Social Subjects no. 15. London: H.M. Stationery Office.

Department of Health and Social Security (1984). Diet and Cardiovascular Disease. Report on Health and Social Subjects no. 28. London: H.M. Stationery Office.

Draper, A., Malhotra, N. \& Wheeler, E. F. (1990). Who are 'vegetarians' and what do they think about food? Proceedings of the Nutrition Society 49,61A.

Dwyer, J. T. (1988). Health aspects of vegetarian diets. American Journal of Clinical Nutrition 48, 712-738.

Food and Agriculture Organization (1988). Requirements of Vitamin A, Iron and Vitamin $B_{12}$. Rome: FAO.

Freeland-Graves, J. (1988). Mineral adequacy of vegetarian diets. American Journal of Clinical Nutrition 48, 859-862.

Freeland-Graves, J. H., Bodzy, P. W. \& Eppright, M. L. (1980). Zinc status of vegetarians. Journal of the American Dietetic Association 77, 655-661.

Gregory, J., Foster, K., Tyler, H. \& Wiseman, M. (1990). The Dietary and Nutritional Survey of British Adults. London; H.M. Stationery Office.

Hardinge, M. G. \& Stare, F. J. (1954). Nutritional status of vegetarians. American Journal of Clinical Nutrition 2, $73-82$

Helman, A. D. \& Darnton-Hill, (1987). Vitamin and iron status in new vegetarians. American Journal of Clinical Nutrition 45, 785-789.

Herbert, V. (1988). Vitamin $\mathbf{B}_{12}$ : plant sources, requirements and assay. American Journal of Clinical Nutrition 48 , $852-858$.

James, W. P. T. (1983). A Discussion Paper on Proposals for Nutritional Guidelines for Health Education in Britain. London: Health Education Council.

Kelsay, J. L., Frazier, C. W., Prather, E. S., Canary, J. J., Clark, W. M. \& Powell, A. S. (1988). Impact of variation in carbohydrate intake on mineral utilization by vegetarians. American Journal of Clinical Nutrition 48, 875-879.

Kies, C. V. (1988). Mineral utilization of vegetarians: impact of variation in fat intake. American Journal of Clinical Nutrition 48, 884-887.

Lewis, J. \& Buss, D. H. (1988). Minerals and vitamins in the British household food supply. British Journal of Nutrition 60, 413-426.

Millet, P., Guilland, J. C., Fuchs, F. \& Klepping, J. (1989). Nutrient intake and vitamin status of healthy French vegetarians and nonvegetarians. American Journal of Clinical Nutrition 50, 718-727.

National Academy of Sciences/National Research Council (1986). Nutrient Adequacy: Assessment Using Food Consumption Surveys. Washington DC: National Academy Press.

Office of Population Censuses and Surveys (1980). Classification of Occupations. London: H.M. Stationery Office.

Paul, A. A. \& Southgate, D. A. T. (1978). In The Composition of Foods. [A. McCance and E. Widdowson, editors]. London: H.M. Stationery Office.

Paul, A. A., Southgate, D. A. T. \& Russell, J. (1980). First Supplement to McCance and Widdowson's The Composition of Foods. London: H.M. Stationery Office.

Reddy, S. \& Sanders, T. A. B. (1990). Haematological studies on pre-menopausal Indian and Caucasian vegetarians compared with Caucasian omnivores. British Journal of Nutrition 64, 331-338.

Roshanai, F. \& Sanders, T. A. B. (1984). Assessment of fatty acid intakes in vegans and omnivores. Human Nutrition: Applied Nutrition 38A, 345-354.

Sanders, T. A. B. (1988). Growth and development of British vegan children. American Journal of Clinical Nutrition 48, 822-825.

Schofield, C., Wheeler, E. \& Stewart, J. (1987). The diets of pregnant and post-pregnant women in different social groups in London and Edinburgh: energy, protein, fat and fibre. British Journal of Nutrition 58, 369-381.

Siegel, S. (1956). Non-parametric Statistics for the Behavioural Sciences. New York: McGraw Hill.

Southgate, D. A. T. (1978). Dietary fibre: analysis and food sources. American Journal of Clinical Nutrition 31, $107-111$.

Tan, S. P., Wenlock, R. W. \& Buss, D. H. (1985). Immigrant Foods, London: H.M. Stationery Office.

World Health Organization (1985). Energy and Protein Requirements: Report of a Joint WHO/UNU Expert Consultation. Technical Report Series no. 724. Geneva: WHO.

Worsley, A. \& Crawford, D. (1988). Dietary supplementers' dietary descriptions, lifestyles and personal values. Ecology of Food and Nutrition 20, 139-156. 